\title{
Tackling the Covid-19 Pandemic in Animal Facilities: ACTREC Perspectives
}

\author{
R.A. Thorat, A.D. Ingle ${ }^{1}$
}

10.18805/ag.R-2089

\begin{abstract}
The Novel Coronavirus outbreak gave learning lesson to the entire world especially about how to fight with the invisible enemy. The scientific community is engaged in exploring the pathogenesis of this Novel disease and inventing the antivirals. At the same time, laboratory animal facility key personnel are busy in carrying out facility operations without compromising the laboratory animal welfare and on-going animal research. In general, every laboratory animal facility establishes the disaster management plan considering the possibility of fire, earthquake, cyclones or flood. Advanced Centre for Treatment, Research and Education in Cancer (ACTREC) Animal Facility also has well documented disaster plan in place. However, incorporation of preparedness plan against disaster due to pandemic was never thought of. However, with our extensive experience, great team efforts and timely decisions, we could continue facility operations without compromising animal welfare, on-going animal research and health of animal care personnel. It is the need of hour to make a preparedness plan in advance to respond to any kind of such pandemics in the future. We wish to share our experience gained during SARS-CoV-2 pandemics. This data is concerned about us but may be helpful to other animal facilities in India and/ or across the globe.
\end{abstract}

Key words: Animal facilities, Pandemic, Tackling, Preparedness.

In late December 2019, a group of people having severe pneumonia caused by severe acute respiratory syndrome coronavirus (SARS-CoV-2) reported from Wuhan, China (Zhu et al., 2019; Li et al., 2020). The initial cluster was epidemiologically linked to a seafood wholesale market in Wuhan, although many of the initial 41 cases were later reported to have no known exposure to the market (Zhu et al., 2019). This was alarming situation for entire global health community sector.

On $30^{\text {th }}$ January 2020, the World Health Organization (WHO) declared that the SARS-CoV-2 outbreak constituted a public health emergency of international concern (Mullen et al., 2020). More than 82,000 confirmed cases were reported worldwide as on $27^{\text {th }}$ February 2020 (WHO, 2020). Considering the severity of global transmission of the virus and number of cases found, on March 11, 2020, WHO has declared the Novel Coronavirus (COVID-19) outbreak as a global pandemic (Cucinotta and Vanelli, 2020).

In today's world due to accessibility in rapid transport system, a pathogen that emerges in one country can easily be transported in people, animals, plants, or food products to distant parts of the world within no time. Entire world is facing the pandemic due to Novel Coronavirus and large numbers of humans are found positive to virus in different parts of the world.

Considering the global pandemic situation and rising number of cases in India, on $22^{\text {nd }}$ March, 2020, India observed a 14-hour voluntary public curfew announced by Hon. Prime Minister of India. On 24 $4^{\text {th }}$ March 2020, the Hon Prime Minister of India ordered a nationwide lockdown for 21 days. By end of March 2020, India had 146 Covid-19 positive cases and by end of June 2020, India recorded
Laboratory Animal Facility, Advanced Centre for Treatment, Research and Education in Cancer (ACTREC), Tata Memorial Centre, Kharghar, Navi Mumbai-410 210, Maharashtra, India.

${ }^{1}$ Homi Bhabha National Institute, Anushaktinagar-400 094, Mumbai, Maharashtra, India.

Corresponding Author: A.D. Ingle, Laboratory Animal Facility, Advanced Centre for Treatment, Research and Education in Cancer (ACTREC), Tata Memorial Centre, Kharghar, Navi Mumbai-410 210, Maharashtra, India. Email: aingle@actrec.gov.in

How to cite this article: Thorat, R.A. and Ingle, A.D. (2021). Tackling the Covid-19 Pandemic in Animal Facilities: ACTREC Perspectives. Agricultural Reviews. 42(2): 203-208. DOI: 10.18805/ag.R-2089.

Submitted: $26-08-2020 \quad$ Accepted: $29-10-2020 \quad$ Online: $23-12-2020$

18522 number of positive cases. With the mandatory lockdown, all the activities like intra- and inter-state movements of personnels were restricted. All the nonessential activities were completely prohibited. To maintain the physical distancing and restrict the spread of virus, Department of Personnel and Training (DoPT), Ministry of Personnel, Public Grievances and Pensions, Government of India issued a notification dated 19.03.2020 about reduction in workforce at very essential service sectors like hospitals, sanitation departments, doctors, paramedical staff, police force etc. The notification also suggested forming different staggered timings to attend the offices by the staff.

Based on this notification, our organization also decided to cease the operations of non-essential departments vide circular dated 25.03.2020. Vide this notification, our Administration identified and permitted to continue the 
wards, diagnostic services, medical oncology, medical stores, operation theatres and laboratory animal facility with skeletal staff. A deadline was issued for the research laboratories to shut down the operations by winding up the on-going research and switching off the non-essential equipment. Even in the deadline period, single staff/ student per bench was permitted in the laboratory. The purpose was to reduce the entry of number of staff attending the office and to minimise the contact between the fellow colleagues. This sudden move had surprised us too. However, with our administrative experience and knowledge of basic laboratory animal science and management, we could continue facility operations without thinking of complete shutdown of animal facility. The next step we did was sending notification on dated 26.03.2020 to all researchers who had their on-going animal study proposals, to terminate the about-completion experiments or minimise the number of experimental animals, wherever possible. We also suspended the animal supply temporarily to start any new experiments. This was a harsh decision but the researchers too understood the gravity of the situation and co-operated by reducing the experimental animals as well as not starting any new experiment. Not only us but the research world over faced similar situation with their experimental animals as well as cell lines and several of them had to sacrifice their animals which were under experimentation and also freeze down the cell lines (Nowogrodzki, 2020).

We were aware that the regular $\mathrm{PhD}$ scholars will be the most affected in the shutdown period as many of their on-going experiments were terminated and no new animal supply was permitted to initiate new experiments. Some of them may have also received the revision of manuscripts with certain deadline to submit the revised manuscripts. But this situation was also faced by all $\mathrm{PhD}$ student community world over (Bardelli, 2020).

Since the numbers of cases were at its low in the country, we decided to start the animal supply to the researchers for their new animal experiments on 27.05.2020. Unfortunately the number of positive cases started rising significantly after mid-July, 2020. By end of July 2020, India recorded 55078 numbers of positive cases. Considering this alarming situation, we had to again reconsider supply of new animal to the researchers. Accordingly, we decided to stop the animal supply again in the last week of July 2020. However, considering the urgency by some of the senior PhD students to complete their thesis, we decided to permit the final year students on their demand and revision cases of manuscripts to initiate even new experiments. To implement this strictly, we even demanded the proof of receipt of revision mails received from the editors. We also suggested the students to strictly follow the PPE code as well as hygiene while entering the animal rooms and also using the face shield when there are two personnel working in close proximity. This has greatly helped us to control the spread of Covid-19 cases from other departments to the Animal Facility and so far there is no reported case of Covid19 positive staff of the Animal Facility.
In this publication, we have shared our experience about how we could succeed to tackle the pandemic situation without compromising animal welfare, on-going animal research as well as health of the animal care staffs.

\section{Laboratory animal facility, ACTREC at a glance}

The Laboratory Animal Facility (LAF) of ACTREC https:// actrec.gov.in/cri-research-support-facility-detail/70, where the present work is carried out, is located in an exclusive and specially designed building with over 15,000 Square feet (1394 Square meter) area spread over two floors. We do maintain immune-competent (11 strains), immunecompromised (2 strains), genetically engineered mouse models ( $\sim 50$ strains), single rat as well as hamster strain to study the basic cancer biology. The main activity of the laboratory animal facility is to breed, maintain and supply quality rodents to in-house investigators as per the requirements. We undertake routine microbiological as well as genetic quality testing of the available small laboratory animals using conventional as well as PCR based methods. Based on the quality control services of the laboratory animals, we do receive nationwide requests for supply of quality laboratory animals which are fulfilled based on the availability of surplus animals. Our facility is an 'Institutional Member' of the International Council for Laboratory Animal Science (ICLAS) https://iclas.org/iclas-membership-list/\#14. ICLAS have even recognized our facility as one of the centres in 'Training and Education' in laboratory animal science.

\section{Organogram of LAF}

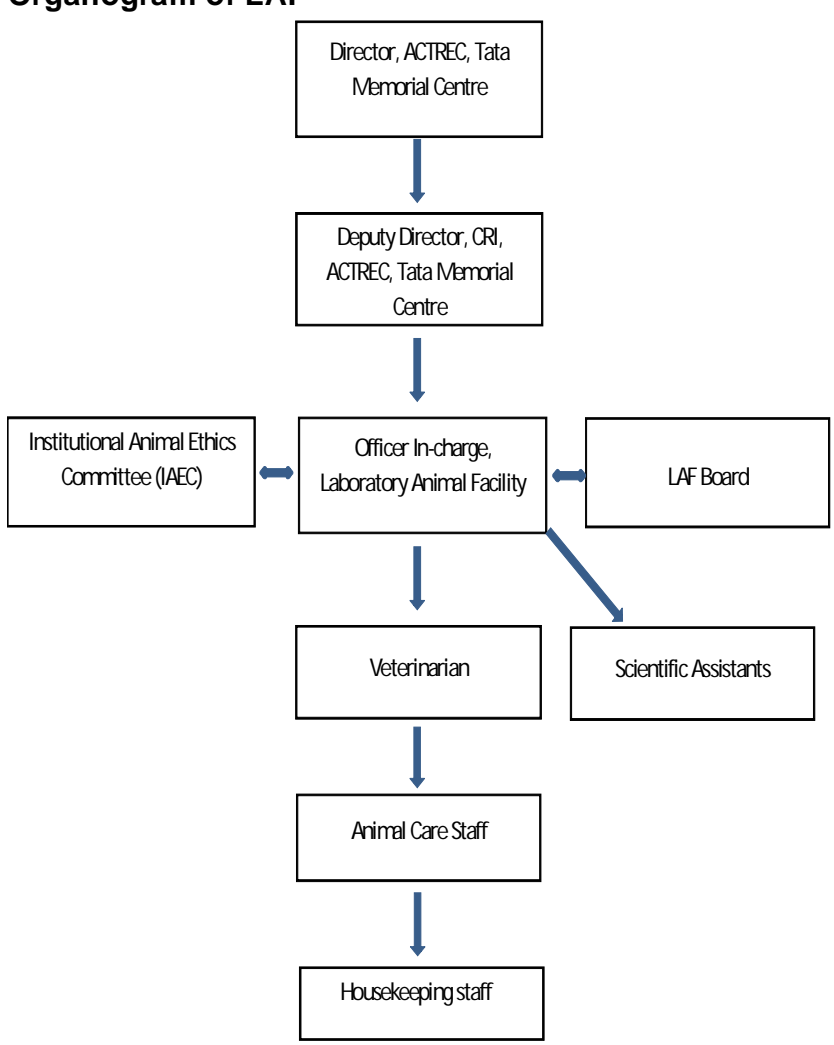

ACTREC Animal Facility has total strength of twenty three personnel including seven housekeeping contract staff, twelve technicians, two scientific assistants and two experienced veterinarians. 


\section{Institutional disaster management plan}

Laboratory Animal Facility, ACTREC has disaster management plan in place to mitigate the effects of disasters like fire, flood or earthquake etc. Animal Facility have safeguarded majority of valuable strains by using assisted reproductive techniques (ART) like embryo and sperm cryopreservation. In order to test the reliability of these techniques at our Facility, in the past we have tested and proved that we are capable of rescuing the original stock of animals by using ART's (Thorat et al. 2013).

In India, the number of positive cases were rising constantly. To stop the spread, a nation- wide lockdown was declared by Government of India. This created a big challenge to all of us. Because neither we had a disaster response plan in place to tackle such pandemic nor did we face such kind of situation before. The DoPT has issued a circular to minimise the number of employees at workplace. Based on the circular of DoPT, ACTREC administration also decided to cease the operations from all non-essential departments vide notification dated 25.03.2020. Worldwide reports suggested that several organisations have to temporarily cease the non-essential services. It is worth mentioning here that the AAALAC International organization has also permitted postponement of the site visits and temporary shutdown of the Animal Care and Use Program (AAALAC, 2020).

As soon as we received the notification from our Administration, we convened the urgent departmental meeting to discuss the strategies to carry out essential duties during the lockdown period. Our main agenda of the meeting was how to carry out day to day facility operations without compromising on animal welfare, on-going animal research and health of the personnels.

\section{We mainly discussed and executed following action plan}

1. Identifying the animal care taker staff including housekeeping staff who stays in the vicinity of the institute and logistics for doing day to day activities.

2. Training and education to staff who will be working during lockdown period.

3. Partial de-population of breeders as well as pre-mature termination of on-going animal experiments in consultation with the researchers.

4. Changes in husbandry practices to save available essential stock.

5. To give updates to the IAEC.

6. How to safeguard the valuable strains.

\section{Animal care taker staff and logistics}

Major impact of pandemic was reduction of workforce in all departments and so also in animal facility. Our main aim was to identify and deploy personnels to take care of daily animal facility operations smoothly. At the same time, we had a challenge of looking after health and safety of personnels during this pandemic period.
Since our routine work distribution is fixed, we knew about the expertise of every individual working in the animal facility. Our facility work is mainly divided into five sections as Veterinary care, Quality control, Immuno-competent animal care, Immuno-compromised animals section and Housekeeping. Keeping this in mind, we planned rotation in duties in such a way that staff who are regularly working in above mentioned sections will attend minimum duties so that the continuity of work like routine checking/ exchanging, quality testing, record updation, numbering, weaning of animals etc. is maintained. No reshuffling of staff between the sections was done.

The next challenge was logistics of rotational duties. Our office is situated away from the Mumbai city and is located in close proximity of two more municipalities. Fortunately, majority of Animal Facility care staff are located within the range of $10 \mathrm{~km}$ of radius from the office. After thorough discussion and suggestions from all the animal care staff, it was decided that the staff who are residing in the vicinity or maximum in $10 \mathrm{~km}$ jurisdiction, will be coming on rotational basis to avoid travelling and exposure of outstationed staffs. Accordingly, staff strength was reduced up to $50 \%$ of the total strength considering there are no local trains/ other public transport running as most of the staff staying beyond $10 \mathrm{kms}$ travel by these modes. One veterinarian was working on every alternate day to look after veterinary care. We decided to do minimal and essential routine quality control checks of animals during lockdown period. The team of 6 personnel were given task to look after all the animal husbandry part. For housekeeping personnels, we instructed contract supervisors to implement for similar arrangements for their personnels. Accordingly housekeeping work force was reduced by half.

Ministry of Fisheries, Animal Husbandry and Dairying, Govt. of India, vide letter number No. 9-16/ 2019-20/PCA dated 24.03.2020, issued a notification that animal facility work comes under essential duties and institution must depute adequate man power to take care of animals. This notification further instructed the law enforcing agencies to allow movement of such staff during lockdown period. With reference to this notification, we provided authorization letters on ACTREC letter head to each staff. Authorization letter helped a lot to our staff while travelling to attend to their duties.

Fortunately, the LAF, ACTREC has no working staff beyond 55 years of age. Similarly, we had no pregnant lady staff working in the LAF making our job easy to manage the manpower (ICMR-NIRRH, 2020).

\section{Training and Education of staff working during lockdown}

After deciding the workforce in all the sections, our next objective was to educate and provide training to everyone. First, we prepared a Standard Operating Procedure (SOP) entitled "To lay down the procedure for prevention from COVID-19 at workplace in LAF, ACTREC". Later, we formed a single group using social media platform app, which helped us to circulate the important notifications/ announcements 
amongst us. This has proved an easy and fast way of effective communications.

All the staffs were educated and trained in basic things e.g. how coronavirus spreads, how to wash hands with soap, use of hand sanitizers, avoid handshakes, mandatory wearing of face masks, avoid touching to nose, face, eyes, compulsory taking shower before we leave the office, staggered breaks or meal times to maintain physical distancing. We also emphasized on them that ensuring strict compliance in the office will not only protect them and the fellow colleagues but will also help their family members to stay away from the Coronavirus. We made entire staff aware that physical distancing helps to mitigate the spread of disease (Glass et al., 2006). We educated our staff to recognise early symptoms like fever, cold, cough, sore throat, body pains or headache and to report immediately to institute staff physician for further health investigations. We pasted pictorial presentation about prevention of disease spread at various locations in the facility. There was provision of hand sanitizers at the main entrance, laboratories, corridors of animal facility, common rooms, washing areas etc. We insisted to download Government of India recommended "Aarogya Setu App" in the smartphones by all staff to assess the health status, evaluate the risk status and Covid-19 cases in nearby surroundings. The Administration has also made mandatory to record temperature of all staff attending duties first time in the morning.

\section{Partial de-population of animals}

Considering, overall global spread of Coronavirus and constant increasing the graph of number of cases in India, we anticipated that the spread of the disease may be severe in India in the coming days. This means there was strong possibility of extension of the lockdown period for few more months. In general, during disasters animals can be relocated from one place to other at safe locations. Relocated animals can be moved back once the conditions are restored. However, during pandemic disaster, this option is not available. Considering this fact, we decided to reduce the number of animal stock. This was for two reasons, one being high risk of animal facility manpower falling sick and increase the absenteeism in such situation. And second for availability of essential stock of animal diet, animal bedding etc. We also decided to put the staff on rotational duties as we reduced the animal population substantially. This way, staffs who have been nominated on rotational basis can work efficiently without much stress of work.

After assessment of animal stock, we communicated to all the researchers to reduce the numbers of cages from the racks and maintain minimum number of cages, wherever possible. We updated them about number of staff working, availability of animal diet/ bedding and possibility of extension of period of lockdown. Accordingly, based upon scientific merits, most of Pl's co-operated and reduced the experimental animals. In case of genetically modified animals, breeding pairs which were already under breeding scheme for transfer of the desired gene into another background strains, could not be depopulated as it took several months of efforts to transfer the gene. We helped the researchers to take the decisions about reducing their research animals.

We did partial depopulation of few of the strains and reduced the numbers of cages from barrier as well as conventional housing rooms. While minimising the breeders, we gave special attention towards strain which have low breeding efficiency so that we can restart our breeding programme in the future without any trouble.

Another matrix applied behind partial depopulation was working capacity of animal care staff. For this, we considered number of cages coming daily for exchanging, number of water bottles for washing and re-filling, numbers of cages for daily checking and observation and regular data entry etc.

Mass euthanasia using carbon dioxide $\left(\mathrm{CO}_{2}\right)$ gas was carried out for depopulation of animals. As numbers of cages were in large numbers, we arranged two euthanasia stations. All euthanasia activity was carried out under the supervision of on duty veterinarian. The standard operating procedure based on American Veterinary Medical Association (AVMA) guideline was strictly followed. The entire carcasses were as usual stored at $-20^{\circ} \mathrm{C}$ till the biomedical waste collection personnel came for the collection. We ensured from the biomedical waste collection personnel supervisor about proper training of personnel who visit the facility to collect the carcasses. Sacrificing the breeder and supply stock to cope up the demand of manpower and feed/ bedding was not only seen limited to us but the necessity was also experienced by the whole world (Nowogrodzki, 2020).

\section{Changes in husbandry practices to save essential stock}

We had a regular frequency of exchanging of mice cages once a week and that of the rat/ hamster cages on twice a week. As numbers of cages were reduced from all the rooms, we decided to change the schedule of cage exchanging. The main purpose behind this was to minimise the staff on non-exchanging days. Accordingly, we decided to exchange all the animal cages on Monday and Friday. Half of the cages were exchanged on Monday and half on Friday. On the day of cage exchanging, the staff strength were six while on remaining non-exchanging days, only two staff were nominated to carry out routine cage checking for feed, water, deliveries, mortality, separation of sick animals etc. We did not compromise on frequency of cage exchanging.

All the bedding waste material were stored in waste disposal room and asked our in-house collection vehicle personnel to take out and dispose the bedding waste on daily basis. This led to reduction of odour and possibility of spread of pathogenic organisms in the animal facility.

Widespread pandemic have resulted in interruption of transportation throughout the nation. The deliveries of essential commodities required for daily facility operations 
like animal feed, animal bedding, Personal Protective Equipment (PPE), disinfectants and other supplies was severely affected. Animal feed and bedding shortage may influence animal welfare of animals. We urgently assessed the situation of available stock of animal feed, bedding, pulses etc. We decided to increase the stock of all essential material and instructed all personnel for judicious use and permission before its use. After depopulation of animals, we predicted that the current stock of animal feed will be sufficient only for short time. The matrix applied behind was per day consumption of animal feed per animals. We even instructed all the staff about not to waste animal feed. We decided to reduce the quantity of bedding material per cage. Reduction of amount of bedding per cage was adjusted such that it did not compromise animal welfare in terms of absorbency of waste material, level of ammonia in cage/ room, burrowing habits of animals etc. We assessed this by daily observation of cages, animal behaviour and human sense of smell in animal colony. Decrease in amount of bedding material in cage led to generation of lesser waste material which in turn reduced the workload on housekeeping staff as well.

As part of the regular PPE for the animal rooms, we had full sleeved T-shirt, Pyjama, disposable surgical head cap/ mask, crocks and nitrile gloves. In this crisis of Covid19 situation, there was a cost escalation and acute shortage of surgical PPE's like disposable face mask/ surgical caps. There was a strong possibility of diminished supply of PPE's; hence we decided to save the stock of PPE's. Incidentally, our organization has made in-house reusable N95 masks and provided ample to all the staff on emergency duties (Walawalkar et al., 2020). We encouraged use of these reusable face masks as alternative types of face masks instead of the regular disposable surgical face masks.

\section{To update Institutional Animal Ethics Committee (IAEC)}

As per the CPCSEA norms, in India IAEC meetings must be convened atleast twice a year. However, considering the number of proposals at ACTREC, we regularly conduct four IAEC meetings a year i.e. on the last Friday of March, June, September and December. Our IAEC meeting was scheduled in the month of March 2020. This was annual meeting wherein our researchers gets approval for animal experimentation for next one year duration. Because of the lockdown and restrictions on physical meeting by the Government and also by the ACTREC Administration, we could not conduct our meeting on scheduled date.

In India, physical IAEC meetings are mandatory to sanction all the animal experimentation protocols. As per rules laid down by CPCSEA, Govt of India, no approval is permitted by distant meeting. Considering the pandemic situation in India and keeping animal welfare in mind, CPCSEA, Govt of India, issued a letter number F. No. 25/ 02/2020-CPCSEA-DADF, dated $13^{\text {th }}$ April 2020 to all establishments mentioning that the organizations may convene their IAEC meetings via video conferencing till the time of emergency conditions due to Covid-19 prevails (CPCSEA, 2020). This is the first time in the history that project approval is allowed by online meeting without physically assembling. Beside this, the CPCSEA also issued two advisories, one for permitting transport of vehicles for transport of feed and fodder and other essential commodities; and second for allowing movement of the employees who are responsible for taking care of the laboratory animals in the laboratory animal houses in the country. Accordingly, we convened two online IAEC meeting one on April 28, 2020 and second on June 04, 2020 and got approval for all the on-going experimentation and new proposals, respectively. During these meetings we updated the IAEC members about the current situation in animal facility and our preparedness to tackle the situation.

\section{Safeguard the valuable strains}

ACTREC laboratory animal facility have mouse embryo cryo repository for in-house usage. We have already cryopreserved some of our valuable strains (Thorat and Ingle, 2012). For embryo collection, we need to euthanize more numbers of donor females and require significant time and efforts. In case of genetically modified strains, it is difficult to obtain several donor females for embryo collection. So we also adopted Sperm cryopreservation to safeguard the genetically engineered mouse models. In this situation of Covid-19 crisis, there has been a surge in requests for cryopreservation of the important strains so that they can be revived after the situation regularises (Nowogrodzki, 2020).

This strategy is helpful to rescue the valuable strains not only during this pandemic situation but also in other kind of catastrophes as well.

\section{Mission begins again}

In the month of May 2020, procedure of lifting of lockdown as Unlock 1.0 was initiated in India and our research groups started reporting in the laboratories. After depopulation of animals, few animal rooms were vacant so we disinfected all the rooms before use. We initiated to expand the breeding of animals to fulfil the animal demands. However, we had still continued to work in minimum numbers of staff to maintain the physical distancing. Because of the number of cases rising every day, the Unlock 2.0 and 3.0 were subsequently announced but with several of the restrictions. While writing this manuscript, we are still in the Unlock 3.0 phase and we expect that the animal facility will function with full capacity within next few months.

\section{CONCLUSION}

Disaster planning is one of the most important tasks in laboratory animal facility. Disaster may come in any form which test facility preparedness to tackle that particular situation. The ultimate aim of the disaster plan is to protect the safety of personnels and laboratory animal wellbeing. Although, we are well prepared to tackle any kind of 
Tackling the Covid-19 Pandemic in Animal Facilities: ACTREC Perspectives

catastrophe, we never thought of including the response plan to tackle pandemic situation due to infectious agents like SARS-Cov-2 virus. Although, laboratory animals are not definitive host for Coronavirus infection due to lack of AchE2 receptors, it is the responsibility of the authority to protect the safety of personnel reporting on duties to carry out all the essential work in the animal facility.

Due knowledge of animal husbandry; expertise in day to day managemental practices; well experienced staff; majority of the staff staying in the close proximity of the office; sufficient stock of consumables, PPE's, animal feed and bedding and good administrative skill helped us to tackle the current pandemic situation. This response plan gave us enough experience for future challenges. However, this pandemic has also taught us of personal hygiene, options of virtual meetings and also gave us opportunity and free time to analyse the old data, complete the half written manuscripts, reading the journals/ books, planning future experiments, attending several of the webinars and last but not least spending quality times with the loved ones.

We hope that such kind of pandemic will never appear again. However, animal facilities must be ready to respond to the pandemics caused due to infectious and/ or zoonotic pathogens.

\section{Conflict of interest}

The authors declare no conflict of interest.

\section{REFERENCES}

AAALAC International FAQs for COVID-19 April 2020. Accessed at https://www. aaalac.org/pub/?id=2636C0F1-BDF6-C7 F4-505D-5633E981D290.

Bardelli, A. (2020). Coronavirus lockdown: What I learnt when I shut my cancer lab in 48 hours. Nature. doi: 10.1038/d41586020-00826-7.

CPCSEA notification http://cpcsea.nic.in/WriteReadData/LnPdf/ IAECmeetingsduringlockdown.pdf.

Cucinotta, D. and Vanelli, M. (2020). WHO Declares Covid-19 a Pandemic, Acta Biomed. 91(1): 157-60.
Glass, R.J., Glass, L.M., Beyeler, W.E., Min H.J. (2006). Targeted social distancing design for pandemic influenza. Emerging Infectious Diseases. 12(11): 1671-1681.

ICMR-NIRRH Guidelines for pregnant women in Covid-19 pandemic. Available at https://www.icmr.gov.in/pdf/covid/techdoc/ Guidance_for_Management_of_Pregnant_Women_in_ COVID19_Pandemic_12042020.pdf.

Li Q., Guan, X., Wu, P., Wang, X., Zhou, L, Tong, Y., et al. (2020). Early transmission dynamics in Wuhan, China, of novel coronavirus-infected pneumonia. The New England Journal of Medicine. 382(13): 1199-1207.

Mullen, L., Potter, C., Gostin, L.O., Cicero, A., Nuzzo, J.B. (2020). An Analysis of International Health Regulations Emergency Committees and Public Health Emergency of International Concern Designations, BMJ Global Health. 5: e002502 doi:10.1136/bmjgh-2020-002502.

Nowogrodzki, A. (2020). Cull, release or bring them home: Coronavirus crisis forces hard decisions for labs with animals. Nature. 580: 19.

Thorat, R. and Ingle, A. (2012). An attempt of cryopreservation of mouse embryos at the ACTREC Laboratory Animal Facility in India. Experimental Animals. 61(2): 139-145.

Thorat, R., Ahire, S. and Ingle, A. (2013). Re-establishment of a breeding colony of immunocompromised mice through revival of cryopreserved embryos. Lab Animmal. 4: 131-134.

Walawalkar, S., Khattry, N., Sapra, B.K., Khan, A., Joshi, M., Mohan, L., Srivastava, S.P., Naresh, C., Badwe, R., Gupta, S. (2020) High Filtration Efficiency Face Masks made from Sterilization Wraps. medRxiv doi: https://doi.org/10.1101/ 2020.05.17.20104638.

World Health Organization. Coronavirus disease (2019). (COVID19): Situation Report - 38. 27 February 2020. Accessed at https://www.who.int/docs/default-source/coronaviruse/ situation-reports/20200227-sitrep-38-covid-19.pdf?sfvrsn $=2 \mathrm{db} 7 \mathrm{a} 09 \mathrm{~b} \_4$.

Zhu, N., Zhang, D., Wang, W., Li, X., Yang, B., Song, J., Zhao, X., Huang, B., Shi W., Lu, R., Niu, P., Zhan, F. (2019). A novel coronavirus from patients with pneumonia in China. The New England Journal of Medicine. 382(8): 727-733 (2020). 